\title{
Microalbumin Status in Relation to Glycated Haemoglobin and Duration of Type 2 Diabetes Mellitus
}

\author{
Kumananda Acharya, ${ }^{1 *}$ Sangita Regmi, ${ }^{2}$ Alina Shri Sapkota, ${ }^{1}$ \\ Mithileshwer Raut, ${ }^{1}$ Bharat Jha ${ }^{1}$
}

BACKGROUND: Diabetes mellitus (DM) is one of the most common endocrine disorders, characterized by hyperglycemia. Diabetic nephropathy is a consequence of long- standing diabetes and urinary microalbumin (Uma) status predicts progression to diabetic nephropathy. This study was conducted to know the status of Uma in relation to duration of diabetes and HbA1c level in patients with Type 2 diabetes mellitus (T2DM).

METHODS: This prospective cross-sectional descriptive study was conducted from July 1, 2014 to January 15, 2015 at TUTH, Kathmandu. Ninety-six known T2DM patients with age 35- 83 years were included in the study. EDTA venous blood and spot urine sample were collected for analysis of $\mathrm{HbA} 1 \mathrm{c}$ and Uma respectively. Only those patients having HbA1c concentration $\geq 6.3 \%$ and duration of diabetes $\geq 6$ months were included under the study.

RESULTS: Overall prevalence of microalbuminuria (MAU) was $39.6 \%$. MAU had a highly significant correlation with duration of diabetes $(r=0.471$, $\mathrm{p}<0.05)$. Present study has shown positive correlation of MAU with $\mathrm{HbA}_{1 \mathrm{c}}$ level, although statistically insignificant $(r=0.245, \mathrm{p}>0.05)$.

CONCLUSIONS: Prolonged exposure to hyperglycemia-induced advanced glycosylation end products accumulations contributes for the development of MAU. So, duration of diabetes mellitus is main contributing factor for the development of MAU rather than HbA1c level alone. Screening for MAU to prevent renal impairment and measuring $\mathrm{HbA}_{1 \mathrm{c}}$ level on a regular basis for good glycemic control are important in diabetic patients.

Key words: Diabetes mellitus, Microalbuminuria, $\mathrm{HbA}_{1}$

(C) 2015 Nepalese Association for Clinical Chemistry

\section{Introduction}

Diabetes Mellitus (DM) is a chronic, widely prevalent endocrine disease, which is characterized by hyperglycemia due to defects in insulin secretion, insulin action or both [1]. Diabetic nephropathy is most common complication of long-standing diabetes mellitus [2]. Persistent microalbuminuria (MAU) is the best predictor of progression to end-stage renal disease (ESRD) as well as cardiovascular complications [3]. Till date, different studies have been performed to find out the relationship between MAU, glycosylated haemoglobin $\left(\mathrm{HbA}_{1 \mathrm{c}}\right)$ and duration of diabetes. All the studies have not shown similar results and the relation between these parameters are not clear. This study was conducted to explore the underlying relationship between these parameters in our context.

\section{Methods}

This prospective cross sectional study was conducted on total 96 patients with T2DM. This study was carried out in Biochemistry Laboratory, Tribhuvan University Teaching hospital (TUTH) from July 1, 2014 to January 15,2015 . In this study, T2DM subjects having $\mathrm{HbA}_{1 c}$ value $>6.3 \%$, who gave written consent were included under this study. Simultaneously, history of duration was taken and required informations were noted. HbA1c was estimated using NyCocard boronate affinity assay and Uma concentration was measured in spot urine sample using NyCocard immunometric assay. NyCocard Reader II was used for measurement of both $\mathrm{HbA}_{1 c}$ and urinary microalbumin. Before performing microalbumin test, the urine sample was tested by uristrip method to exclude overt proteinuria from this study. MAU was diagnosed if albumin was between $20-200 \mathrm{mg} / \mathrm{L}$.

Statistical analysis was done using SPSS version 17.0. Pearson's correlation was applied to observe associations of microalbuminuria with duration of diabetes and $\mathrm{HbA}_{1 \mathrm{c}}$ level. All $\mathrm{p}$-values $<0.05$ were considered as statistically significant.

\section{Results}

A total of 96 patients 54 males and 42 females

\footnotetext{
'Department of Biochemistry, Maharajgunj Medical Campus, IOM, TU, Kathmandu, Nepal; ${ }^{2}$ Manmohan Cardiothoracic Vascular \& Transplant Center, Institute of Medicine, TU, Maharajgunj, Kathmandu, Nepal
}

Correspondence to: Kumananda Acharya, Maharajgunj Medical Campus, Institute of Medicine, Tribhuvan University, Kathmandu, Nepal. E-mail: shinning_kuma@iom.edu.np 
were included in this study. Overall prevalence of MAU in the present study was $39.6 \%(38 / 96)$. Among total 54 males, prevalence of UMA was $44.4 \%$ (24/54). And among 42 females, prevalence of UMA was $33.3 \%$ (14/42). Mean age of patients with UMA was $61.42 \pm 7.45$ years and in normoalbuminuric patients it was $59.21 \pm 8.49$ years.

Duration of diabetes ranged between 6 months and 18 years. Out of total 96 patients, 52 had duration of diabetes $<5$ years and among them 18 (34.6\%) had MAU. Twenty six had duration of diabetes $\geq 5$ to 10 years, among them 10 (38.5\%) had MAU. Twelve had duration of diabetes $\geq 10$ to 15 years, among them $6(50.0 \%)$ had MAU, and six had duration of diabetes $\geq 15$ years, among them $4(66.7 \%)$ had MAU [Table. 1]. Mean duration of diabetes in microalbuminuric patients was $7.71 \pm 5.65$ years while in normoalb- uminuric patients it was $5.17 \pm 4.32$ years, which was statistically significant. Pearson correlation analysis showed statistically significant correlation of MAU with duration of diabetes $(r=0.471, \quad p$ $<0.05$ ) [Table 3].

Out of total 96 patients, 60 had $\mathrm{HbA}_{1 \mathrm{c}}$ level < $8.0 \%$, among them $20(33.3 \%)$ had MAU. 20 had $\mathrm{HbA}_{1 \mathrm{c}}$ level $\geq 8.0-10.0 \%$, among them 10 (50\%) had MAU. 12 had $\mathrm{HbA}_{1 \mathrm{c}}$ level $\geq 10.0$ $12.0 \%$, among them $6(50 \%)$ had MAU 4 had $\mathrm{HbA}_{\mathrm{lc}}$ level $\geq 12.0 \%$, among them $2(50 \%)$ had MAU [Table 2]. Mean $\mathrm{HbA}_{1 c}$ level in microalbuminuric patients was $8.63 \pm 1.89 \%$ while in normoalbuminuric patients it was $8.02 \pm 1.77 \%$. Although MAU positively correlated with $\mathrm{HbA1c}$ but statistically was insignificant. Pearson correlation analysis did not show statistically significant correlation of MAU with HbA1c level $(\mathrm{r}=0.245 \mathrm{p}>0.05)$ [Table 3$]$.

Table 1 :Prevalence of microalbuminuria in relation to duration of T2DM

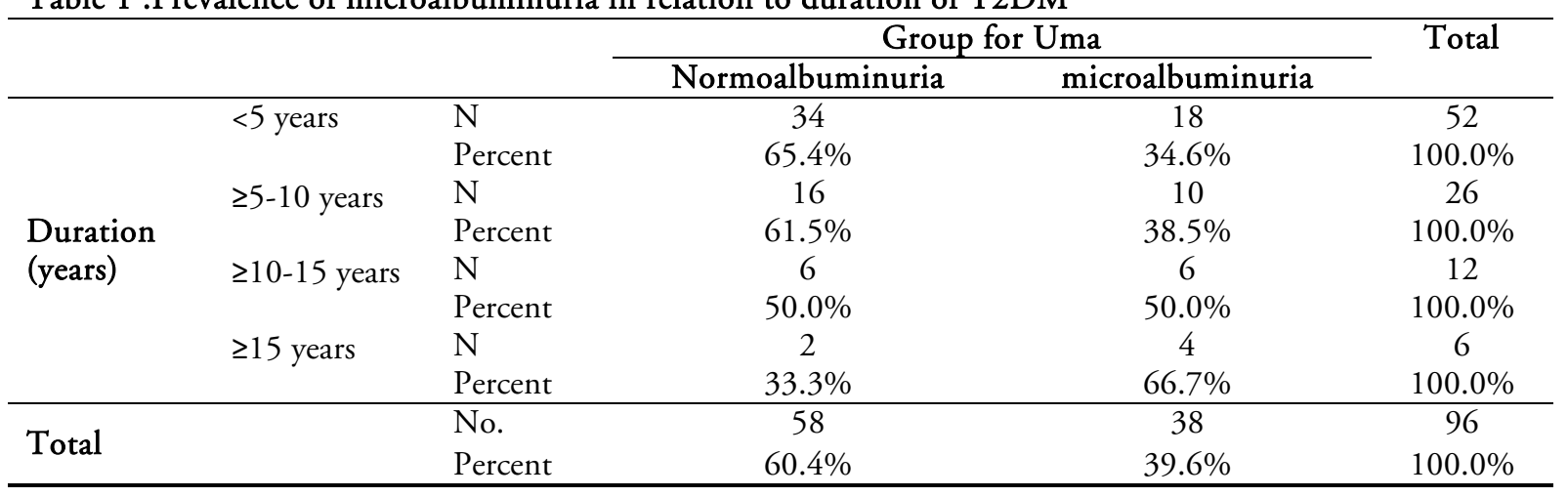

Table 2:Prevalence of microalbminuria in relation to HbA1c level in T2DM

\begin{tabular}{|c|c|c|c|c|c|}
\hline & & & \multicolumn{2}{|c|}{ Group for Uma } & \multirow[b]{2}{*}{ Total } \\
\hline & & & Normoalbuminuria & Microalbuminuria & \\
\hline \multirow{8}{*}{$\begin{array}{l}\text { HbAlc } \\
\text { level (\%) }\end{array}$} & $<8$ & $\mathrm{~N}$ & 40 & 20 & 60 \\
\hline & & Percent & $66.7 \%$ & $33.3 \%$ & $100.0 \%$ \\
\hline & $\geq 8-10$ & $\mathrm{~N}$ & 10 & 10 & 20 \\
\hline & & Percent & $50.0 \%$ & $50.0 \%$ & $100.0 \%$ \\
\hline & $\geq 10-12$ & $\mathrm{~N}$ & 6 & 6 & 12 \\
\hline & & Percent & $50.0 \%$ & $50.0 \%$ & $100.0 \%$ \\
\hline & $\geq 12$ & $\mathrm{~N}$ & 2 & 2 & 4 \\
\hline & & Percent & $50.0 \%$ & $50.0 \%$ & $100.0 \%$ \\
\hline \multirow[t]{2}{*}{ Total } & & $\mathrm{N}$ & 58 & 38 & 96 \\
\hline & & Percent & $60.4 \%$ & $39.6 \%$ & $100.0 \%$ \\
\hline
\end{tabular}


Table 3: Correlation microalbuminuria with duration and HbA1c level in T2DM

\begin{tabular}{lcccc}
\hline Variable & Normoalbuminuria & Microalbuminuria & P value & Correlation coefficient (r) \\
\hline Mean duration (years) & $5.17 \pm 4.32$ & $7.71 \pm 5.65$ & $0.001^{*}$ & 0.471 \\
Mean HbA1c level (\%) & $8.02 \pm 1.77$ & $8.63 \pm 1.89$ & $>0.05^{* *}$ & 0.245 \\
\hline *Statistically significant & & & &
\end{tabular}

**Statistically insignificant

\section{Discussion}

The aim of present study was to explore the prevalence and associations of MAU with different parameters in T2DM in our context. Present study has shown overall prevalence of MAU to be $39.6 \%$. Wu et al has reported slightly higher prevalence of MAU (39.8\%) in Asian population, [4] whereas, another Asian study has shown 36.3\% MAU in T2DM Indian population [5] The overall prevalence of MAU in present study is higher than the study done in Kathmandu valley, Nepal by Maharjan et al, [6] which was $36.79 \%$ but was lower than the study done in Pokhara, Nepal by Sigdel et al, [7] which was $45.5 \%$. Prevalence of MAU was reported 25 $\%$ in one study conducted by Ghai et al. [8]. This marked variation in results for prevalence of MAU might be due to sample size, sample selection, study design, hypertension, poor glycemic control, duration of diabetes, age and gender structure of study population.

Present study has shown significant correlation of MAU with duration of diabetes which is in accordance with many previous reports [9]. Chowta et al showed statistically significant correlation of MAU with duration of diabetes ( $\mathrm{r}$ $=0.839, \mathrm{p}<0.0001)[10] . \mathrm{Naz}$ et al had reported similar type of result in patients from Islamabad and Rawalpindi [11].

This study has shown positive correlation of MAU with $\mathrm{HbA1c}$, but statistically insignificant $(\mathrm{r}=0.245, \mathrm{p}>0.05)$. In a study conducted by Maharjanet al in Kathmandu valley, Nepal comparison of $\mathrm{HbAlc}$ level between microalbuminuric and normoalbuminuric was not statistically significant [6].ShonimaVenugopal and Uma M lyer showed statistically significant correlation of UMA and HbA1c level $(\mathrm{p}<0.05)$ [12].Manjrekar et al has reported gradual increase in prevalence of MAU with similar increase in HbAlc level [13].Similarly, Gupta et al performed an independent study and reported strong association of HbAlc level with urinary microalbumin excretion [14]. The difference in results may be due to limited sample size. Hence, further study with a larger sample is necessary in order to confirm the result obtained in present study.

This study shows conclusive evidence that urinary microalbumin excretion was significantly correlated with duration of the disease and level of $\mathrm{HbAlc}$ positively correlated with urinary microalbumin although statistically insignificant. Duration of diabetes contributes for the development of MAU and then diabetic nephropathy by prolonged exposure to hyperglycemia induced advanced glycosylation end products.

\section{Conclusion}

Overall prevalence of microalbuminuria in T2DM was $39.6 \%$. Urinary microalbumin excretion correlated significantly with duration of diabetes. Increased $\mathrm{HbA1c}$ level positively correlated with MAU, although statistically insignificant. Regular screening for urinary microalbumin as well as HbA1c and good glycemic control is recommended in such patients.

\section{Acknowledgement}

We are grateful to the entire team of Department of Biochemistry, TU Teaching Hospital, Kathman-du, Nepal for their great support throughout the study.

\section{REFERENCES}

1. American Diabetes Association Diagnosis and classification of diabetes mellitus. Diabetes care. 2008;31(Supplement 1):S55-S60.

2. Fowler MJ. Microvascular and macrovascular complications of diabetes. Clinical diabetes. 2008;26(2):77-82.
3. Maiti A, Raychaudhuri P, De J, Mukhopadhaya S, Dey SK, Sinha $\mathrm{PK}$, et al. Changes in Microalbuminuria in Relation to Glycosylated Haemoglobin (HbA1c) and Duration in Type 2 Diabetes Mellitus.
4. Wu A, Kong N, De Leon F, Pan C, Tai T, Yeung V, et al. An alarmingly high prevalence of diabetic nephropathy in Asian type 2 diabetic patients: the MicroAlbuminuria Prevalence (MAP) Study. Diabetologia. 2005;48(1):17-26. 
5. Varghese A, Deepa R, Rema M, Mohan V. Prevalence of microalbuminuria in type 2 diabetes mellitus at a diabetes centre in southern India. Postgraduate medical journal. 2001;77(908):399402.

6. Maharjan B, Bhandary S, Risal P, Sedhain A, Gautam M. Microalbuminuria and macroalbuminuria in type 2 diabetes. Journal of Nepal Health Research Council. 2011.

7. Sigdel M, Rajbhandari N, Basnet $S$, Nagila A, Basnet P, Tamrakar B. Microalbuminuria among type-2 diabetes mellitus patients in Pokhara, Nepal. Nepal Med Coll J. 2008;10(4):242-5.

8. Ghai R, Verma N, Goel A, Bhatnagar M, Kapoor P, Vashishta A. Microalbuminuria in non insulin dependent diabetes and essential hypertension: a marker of severe disease. The Journal of the Association of Physicians of India. 1994;42(10):771-4.

9. Sheikh SA, Baig JA, Iqbal T, Kazmi T, Baig M, Husain SS. Prevalence of microalbuminuria with relation to glycemic control in type-2 diabetic patients in Karachi. J Ayub Med Coll Abbottabad. 2009;21(3):83-6.

10. Chowta N, Pant P, Chowta M. Microalbuminuria in diabetes mellitus: Association with age, sex, weight, and creatinine clearance. Indian journal of nephrology. 2009;19(2):53.

11. Naz S, Sadaruddin A, Khannum A, Osmani R. Frequency of microalbuminuria in diabetic patients of Islamabad and
Rawalpindi. Pak J Med Res. 2007;46(3):70-4.

12. Venugopal S, Iyer UM. Risk Factor Analysis and Prevalence of Microalbuminuria among Type 2 Diabetes Mellitus Subjects: The Need for Screening and Monitoring Microalbumin. Hip (cm). 2010;95(7):105-11.

13. ManjrekarPoornima A, Shenoy R, Hegde A. Laboratory Assessment of the Diabetes Scenario with Respect to $\mathrm{HbA1c}$ and Microalbuminuria. Journal of Clinical and Diagnostic Research. 2010;4:2489-94.

14. Gupta D, Verma L, Khosla P, Dash S. The prevalence of microalbuminuria in diabetes: a study from north India. Diabetes Research and clinical practice. 1991;12(2):125-8. 